\title{
e emeraldinsight
}

\section{Qualitative Market Research: An International Journal}

Consumed by the real: A conceptual framework of abjective consumption and its freaky vicissitudes

George Rossolatos,

\section{Article information:}

To cite this document:

George Rossolatos, (2018) "Consumed by the real: A conceptual framework of abjective consumption and its freaky vicissitudes", Qualitative Market Research: An International Journal, Vol. 21 Issue: 1, pp.39-62, https://doi.org/10.1108/QMR-10-2016-0091

Permanent link to this document:

https://doi.org/10.1108/QMR-10-2016-0091

Downloaded on: 10 J anuary 2018, At: 07:25 (PT)

References: this document contains references to 75 other documents.

To copy this document: permissions@emeraldinsight.com

The fulltext of this document has been downloaded 9 times since 2018*

Access to this document was granted through an Emerald subscription provided by

Token: Eprints: WZZKGV4J HJ D6EIP3J 6UK:

\section{For Authors}

If you would like to write for this, or any other Emerald publication, then please use our Emerald for Authors service information about how to choose which publication to write for and submission guidelines are available for all. Please visit www. emeraldinsight.com/ authors for more information.

\section{About Emerald www.emeraldinsight.com}

Emerald is a global publisher linking research and practice to the benefit of society. The company manages a portfolio of more than 290 journals and over 2,350 books and book series volumes, as well as providing an extensive range of online products and additional customer resources and services.

Emerald is both COUNTER 4 and TRANSFER compliant. The organization is a partner of the Committee on Publication Ethics (COPE) and also works with Portico and the LOCKSS initiative for digital archive preservation.

*Related content and download information correct at time of download. 


\section{Consumed by the real A conceptual framework of abjective consumption and its freaky vicissitudes \\ George Rossolatos \\ University of Kassel, Kassel, Germany}

Framework of abjective consumption

Received 5 October 2016 Accepted 10 October 2016

\begin{abstract}
Purpose - This paper furnishes an inaugural reading of abjective consumption by drawing on Kristeva's psychoanalytic theory of abjection within the wider terrain of consumer cultural research. It offers a conceptual framework that rests on three pillars, viz. irrationality, meaninglessness, dissolution of selfhood.
\end{abstract}

Design/methodology/approach - Qualitative research design that adopts a documentary ethnographic approach, by drawing on a corpus of 50 documentary episodes from the TV series "My Strange Addiction" and "Freaky Eaters".

Findings - The findings from this analysis point to different orders of mediatized discourse that are simultaneously operative in different actors' frames (e.g. moralizing, medical), in Goffman's terms, yet none of which attains to address the phenomenon of abjective consumption to its fullblown extent.

Research limitations/implications - Although some degree of bias is bound to be inherent in the data because of their pre-recorded status, they are particularly useful not in the least because this is a "difficult sample" in qualitative methodological terms.

Practical implications - The multi-order dimensionalization of abjective consumption opens up new vistas to marketers in terms of adding novel dimensions to the message structure of their communicative programs, in line with the three Lacanian orders.

Social implications - The adoption of a consumer psychoanalytic perspective allows significant others to fully dimensionalize the behavior of abjective consumption subjects, by becoming sensitive to other than symbolic aspects that are endemic in consumer behavior.

Originality/value - This paper contributes to the extant consumer cultural research literature by furnishing the novel conceptual framework of abjective consumption, as a further elaboration of my consumer psychoanalytic approach to jouissance consumption, as well as by contrasting this interpretive frame vis-àvis dominant discursive regimes.

Keywords Goffman, Abjection, Frame analysis, Consumer cultural research,

Documentary ethnography, Kristeva

Paper type Research paper

\section{Introduction}

To effectively contextualize abjective consumption within the conceptual terrain of consumer cultural research, it is prudent to begin by engaging in a contrastive reading between this newly articulated mode of consumption, fundamental tenets of consumer behavior and the time-hallowed perspective of symbolic consumption. The differences that will emerge through this reading will aid us in the following sections to appreciate more narrowly why abjective consumption is a useful perspective within the conceptually overpopulated domain of consumer behavior:

Consumption (...) includes any form of acquisition, usage or disposition directed toward consummation in the satisfaction of needs and wants. This means that consumption encompasses

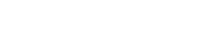


QMR 21,1

any behavior that confers value and that thereby reflects the influence of underlying motivations. Hence, by motivating its reflection of needs and wants, consumption mirrors a dramatic character's disposition and helps to reveal the nature of the personality (Hirschman and Holbrook, 1993, p. 236).

Consumption is customarily viewed as a process involving goal-orientedness, deliberation, voluntary actions and underlying motivations (Baumgartner and Pieters, 2008; Janiszewski, 2008), all underpinned by an omnipresent sense of selfhood. This knitty gritty picture has been severely challenged in the context of postmodern consumptive patterns (Sherry, 1991; Firat and Venkatesh, 1995; Firat and Dholakia, 2006; Bauman, 2007; Featherstone, 2007) where ephemeral, non-functional and often irrational benefits (Arnould and Thompson, 2005) predominate, especially for product categories such as those on offer in the entertainment business. Moreover, as shown by Elliott (1997) and Elliott and Wattanasuwan (1998), irrational desire is in fact operative as a "motivating principle" behind even mundane consumptive acts. This principle is often underpinned by existential benefits that cut through the veil of seemingly rationalizable benefits, need-states and wants. Irrational desire, though, according to Elliott and Wattanasuwan (1998) is still mediated by the symbolic meaning that is ascribed to brands by specific consumer groups in quest for a cultural identity. This identity is negotiable according to the multiple consumptive contexts wherein a consumer may be embedded; hence, brands constitute springboards for the situational enactment of multiple identities (Schenk and Holman, 1980). Despite the acknowledgment of the potentially variegated symbolic meanings with which brands are invested, Elliott and Wattanasuwan (1998) do not consider cases where brands may not be symbolically invested at all, as well as cases where the consumption of symbolic products may be utterly meaningless. This is partially attributed to a non-appreciation of the fact that although all brands are signs, not all signs are symbolic (Rossolatos, 2015d). The assignment of symbolic status to a brand implies and necessitates the incidence of a convention [or "code" in Eco's (1975) terms; also see Rossolatos (2014) with regard to different levels of codedness], or "cultural code" with regard to branding [Schroeder (2009), or "key" in Goffman's (1974)] terms, which Goffman explicitly recognized as being equivalent to "meaning convention" and to the semiotic conception of "code" [cf. Goffman (1974), p. 44, ft.14] whereby a specific meaning is attributed to a brand. This convention is recognizable by and shared among the members of a consumer group/segment. However, brands occasionally have highly individual meanings that constitute instances of divergent signification vis-à-vis conventional, symbolic meanings. Elliott and Wattanasuwan (1998) recognize the possibility of individual, idiosyncratic brand meanings, however still consider such meanings as being accountable by the perspective of symbolic consumption. This conceptual accommodation, however, constitutes an oxymoron, as to confer symbolic status to a brand as sign, a widely shared signifying convention should be recognized. Therefore, idiosyncratic meanings are possible for brands; however, these meanings are by definition not symbolic. In fact, as noted by Caslav (2004, p. 22), "the abject is also what is suppressed and repressed within and through symbolic language". This standpoint urges us to reconsider the way brand meaning (or lack thereof) shapes up from an abjective consumption perspective, as it diverges markedly from consumer cultural theory orthodoxies that assume agentic reflexivity and consumer empowerment through engagement in micro-communities (Askegaard and Trolle Linnet, 2011) as given. On the contrary, "abject politics is an oxymoron, because the subjecthood and solidarity needed for a politics is devastated by abjection's dissolution of identity" (Caslav, 2004, p. 133).

The second area where the perspective of symbolic consumption is wanting concerns instances of consumption where meaning is lacking altogether. Although scarce, given that 
even unconscious motives are subsumable under brand signification processes, while irrational motives are not precluded outright as capable of investing brands with meaning, it is not impossible to envision such cases. This may be attained by correlating consumptive acts not with unconscious motives, but with responses to non-ego driven demands placed upon subjects by a field of absolute exteriority. Absolute exteriority, here, points to an originary realm of pre-objectification, that is prior to reducing objects to representable entities. This is the space of non-culture, also called "khora" or "khoric space" or "third realm" by Kristeva (1982; also see Derrida, 1992), a space that gives rise to cultural oppositions and to signs as cultural representations. Despite not being representable as such, this space still operates under a "repressive regime" as a silent correlate of consumers' conative acts. This "space" is quasi-equivalent to the Lacanian order of the Real, that is the order of non-discursively mediated "needs" and drives that are meaningless, precisely because of the impossibility of accommodating them under any possible signs. Although, as we shall see in greater detail in the following section, this inherent meaninglessness constitutes a pillar of abjective consumption, it should be borne in mind that the correlation of different "attitudinal states" with the three Lacanian orders (Homer, 2005), that is need/ Real-demand/Imaginary-desire/Symbolic, is not as clear-cut. Rather, it should be viewed as a simplification of the interactions among the three states, inasmuch as there is ongoing interaction among the three orders. "Desire tends to organize itself in relation to the other by means of what Lacan describes as the retroactive effect of demand on need" (Dor and Gurewich, 2010, p. 181).

The realm of the Real "is not" insofar as "it" cannot be framed representationally, save for being experienced intensely as unmediated corporality and materiality. The Real may not be encapsulated either in the Imaginary or the Symbolic orders (Homer, 2005; Rossolatos and Hogg, 2013), save for being experienced as intense and usually repetitive consumptive acts. The meaning of these acts may not be articulated as such, that is as encounters with the order of the Real, without implying that meaningful, yet aberrant and underdetermining, glosses are not feasible.

The concept of abjection and concomitantly of abjective consumption are particularly apt for accounting for these two ubiquitous instances of consumption, that is for non-symbolic consumption and for non-meaningful consumption that transgress and threaten the integrity of ego and super-ego (Kristeva, 1982). To demonstrate the usefulness of this construct, this paper pursues the following expository and illustrative paths. The concept of abjection is introduced and critically discussed in the context of Kristeva's (1982) seminal reading, complemented by detours toward Lacan whose influence on its development has been paramount. The concept's implications for dominant "symbolic" brand significations in a given cultural order are critically addressed. Then, the interpretive lens proceeds for the purposes of illustration with an examination of concrete cases of abjective consumption by recourse to a corpus from the "Freaky Eaters" and "My Strange Addiction" TV series (Appendix, Table AI). The corpus is analyzed by outlining the various frames (in the vein of Goffmanian frame analysis; cf. Goffman, 1974) and the distinctive discursive orders whereby abjective consumption is represented in mediatized discourse.

\section{Irrationality, meaninglessness, loss of selfhood: the three pillars of abjective consumption}

The purchase, use and exchange of objects as cultural artifacts in the context of the formation and transformation of self and collective identity constitutes one of the most heavily researched streams among a plethora of neighboring disciplines, such as cultural/ media studies, cultural anthropology, cultural sociology, semiotics and consumer research.
Framework of abjective consumption 
QMR 21,1

However, the concept of "abject" that surfaced in the humanities in the 80 s and has been catapulted to mainstream academic conceptual currency ever since, has not garnered its due attention among contemporary consumption theories and empirical research. This paper aims at filling this crucial gap, while paving the way for further exploration into an indispensable facet of the "dark side" of consumption.

Perhaps the most representative theorist of abjection who spawned a much discussed monograph on the subject is Julia Kristeva with her Powers of Horror: An Essay on Abjection (Kristeva, 1982). In this work, Kristeva approaches the phenomenon of abjection and abjects as artifacts largely from a psychoanalytic point of view, informed mainly by Lacanian psychoanalysis in conjunction with her own semiotic strand of semanalysis, and exemplified by recourse to theological and literary texts. Although the composition style of this work lies somewhere in between literary prose and literary criticism, interspersed with psychoanalytic and philosophical insights, its key premises may be distilled and critically addressed, at least as regards their relevance to the scrutinized consumer cultural phenomenon. Thus, for the purposes of the expository task at hand, the key conceptual aspects of the abjection construct we shall be concerned with are the ontological status of abject as non-object versus products/brands as objects of desire, the non-fetishistic character of abjects, the process of abjection as consuming or, rather, as being consumed by abjects and the implications of abjection for consumer identity and selfhood at large. Once these crucial facets of abjection will have been effectively elucidated, I shall proceed with contextualizing them under the three conceptual pillars of abjection, viz. irrationality, meaninglessness and dissolution of selfhood. These pillars, in turn, will inform the offered interpretation as to how abjection is actually operative versus how it has been explicitly framed within the mediatized cases that make up our corpus.

Beginning with the delineation of "abject", it is:

[...] not an ob-ject facing me, which I name or imagine. Nor is it an ob-jest, an otherness ceaselessly fleeing in a systematic quest of desire. What is abject is not my correlative, which, providing me with someone or something else as support, would allow me to be more or less detached and autonomous. The abject has only one quality of the object-that of being opposed to I (Kristeva, 1982, p. 1).

Despite Kristeva's allegedly cryptic writing style, it is evident that she adopts an antiepistemic posture vis-à-vis the abject by distinguishing it initially from ordinary objects, and, then, by situating it in a space that is beyond the epistemic purview of a knowing subject (an "I"). The abject's non-correlative ontological status with regard to a subject displaces it immediately not only from a Husserlian phenomenological habitat, but also from space as condition of phenomenality and objectification, according to a Kantian transcendental idealist perspective. The impossibility of knowing what an abject is implies that no properties may be assigned to it. Thus, from a branding point of view, it is impossible to claim that a product is consumed as abject because it possesses attributes $\mathrm{X}, \mathrm{Y}, \mathrm{Z}$. This point will become particularly relevant while discussing the abjective consumption cases in our corpus later on. According to Kristeva, the only thing we may know about an abject as property and defining of its ontological status is that it is opposed to a knowing self, or, in other words, that it lies in a non subject conditioned spatiality that is opposite a knowing subject. From such premises, the conclusion to which Kristeva (1982, p. 2) is drawn, viz. that the abject is a "'something' that I do not recognize as a thing” assumes cogency. Thus, even though a product as object may carry symbolic properties for an enculturated subject, its potential function as abject for a subject would instantly entail its deprivation of any symbolic meaning. Indeed, "what is abject [...] is radically excluded and draws me toward the place where meaning collapses" (Kristeva, 1982, p. 2). Yet, despite their "being-there" 
irreducibly and their seeming ontological status as mere "waste", subjects are occasionally drawn almost pathologically to abjects. Subjects do not consume abjects, but are consumed by them.

To shed further light onto this process of abjection, the exposition of Kristeva's account is called for. Now, although abjects are unknowable, they are not beyond the subject's experiential nexus. However, we are confronted with a sort of pre-reflective, ineffable rapport, a drawing into, that may be rationalized ex post facto, but not encapsulated within a determinate benefit structure that is actively sought by the subject who experiences abjection as a process of being related to abjects. In other words, the subject does not consume abjects because he seeks to fulfill the desire for properties X, Y, Z. However, the experience of abjection may become rationalized as a desire for determinate properties inherent in the abject with which the subject relates, as a secondary elaboration/ rationalization of the ineffable experience with a non-object that lies opposite the consuming subject.

The establishment of a relationship with abjects has been described exclusively in affective terms, and specifically as disgust by Kristeva, as nausea by Sartre, as laughter by Bataille (Menninghaus, 2003). "Food loathing is perhaps the most elementary and most archaic form of abjection" (Kristeva, 1982, p. 6). The affective response of disgust in the face of abjection lets shine forth its peculiar form of spatiality as khoric (third) space, in between inside (subject) and outside (external environment), insofar as disgust at the same time interiorizes and exteriorizes the abject. This is why the abject is ontologically indeterminate, as it may not be located, save for being experienced in all its tantalizingly oscillating ambivalence in the in-betweeness of the affective response. Kristeva goes much further in her pursuit of the meaning of abjection by presenting progressively stronger arguments as to why abjection is in fact responsible for the very constitution of subjectivity and culture at large; however, these arguments by far exceed the analytical focus of this paper. What is of primary importance for our analytic is to unpack how abjection is experienced affectively as a double movement from a non-appropriatable outside (by the subject) and toward a provisionally experienced interiority: "I abject myself within the same motion through which 'I' claim to establish myself' (Kristeva, 1982, p. 3). This paradoxical adverse function of the abject as impossible correlate of the subject that is experienced in an affective state of disgust and nausea is at the same time a remarkable instance of what was termed by Rossolatos and Hogg (2013) jouissance consumption. Jouissance, in Lacanian terms, denotes an affective state where pleasure and pain are experienced as being co-existent, particularly evident in "mystical" experiences (that is sublimated because of the breakdown of the conscious/unconscious distinction, as noted by Kristeva, 1982, p. 7). Rossolatos and Hogg (2013) applied the concept jouissance consumption, as a peculiar case that may not be accommodated by hedonic consumption to account for consumptive experiences, such as the attendance of a live-show by loyal fandom, that are marked precisely by the paradoxical co-existence of deriving pleasure from a highly-involving spectacle, and pain from the impossibly reducible distance that separates an artist as simulacrum on stage and the viewing audience. In that study, Rossolatos and Hogg (2013) did indeed find that experiencing subjects were sustained in an in-between, trance-like state. The same affect is ratified by Kristeva as being defining of abjective disgust: "Hence, a jouissance in which the subject is swallowed up but in which the Other, in return, keeps the subject from foundering by making it repugnant" (Kristeva, 1982, p. 9).

Having, thus far, outlined what is (and what is not) an abject, abjection and where the self sits with regard to abjects and the process of abjection, it should be clarified that abjects are not the same as fetishes. This is a crucial distinction because the concept of "fetish"
Framework of abjective consumption 
QMR 21,1

constitutes one among the few, yet repeatedly, borrowed from psychoanalysis and applied in consumer research. Abjects as cultural artifacts, including brands, are hyper-cathected (that is libidinally over-invested) in highly individual-centric ways, which do not necessarily reflect either their functional or their exchange value. They may be conflated with fetishes insofar as the latter are also characterized by a state of over-cathexis. However, as pointed out by Chanter (2008, p. 59) "abjection can be read, in this context, as an archaic mapping out of the dread that is covered over by the invention of fetishistic discourse". Again, it is at an affective level that the distinction between abject and fetish surfaces at its most manifest. The abject is more primordially experienced against the fetish by virtue of surfacing as dreadful, and even more as vertiginal loss by subjects in its absence. At the same time, this vertiginal state experienced by the subjects who are drawn into abjection, as will be shown more concretely in the empirical prong of this study later on, urges us to critically reevaluate the oft cited affective states in the extant literature of nausea and disgust. This reevaluation concerns the different modes of relationship of the subjects who experience abjection, mainly between those who experience it directly and hence are directly affected, as against those who experience it indirectly by dint of being related (family, friends) to subjects who are directly affected by abjects. Insofar as social situations involving more than one social actors is the focus of our analytic, this distinction will be fully elaborated while addressing particular cases of abjection in the context of mediatized discourses. Let it be noted, in passing, that Butler (1993) further elaborated psychoanalytically on Kristeva's initial conceptualization of abjection, largely within a gender studies terrain. Butler's focus lies more narrowly with the social implications of abjective or repudiated bodies within a given symbolic order, while recognizing, in line with Kristeva, the paradoxical nature of abjection insofar as it demarcates an absolute exteriority or "zone of unlivability", in Butler's terms, by virtue of which the symbolic may be sustained as such.

Pursuant to elaborating on the phenomenon of abjection, the introductory contrastive reading between symbolic consumption and abjection will now be resumed, with a view to identifying the three conceptual pillars of abjection (irrationality, meaninglessness, dissolution of selfhood) as a consumptive phenomenon.

By irrationality I mean a failure on behalf of subjects drawn into abjection to effectively subsume these consumptive acts under a rational calculus and, hence, to weigh benefits over material and psychological expenses, coupled with a sheer and unconditional surrender (giving in) to the abject. The subject does not consume the abject, but is drawn by (Kristeva, 1982, p. 2) and withdrawn into it as if by a meaningless black hole that mesmerizes and magnetizes those who attempt to enter its realm. What is ultimately "sought" by these subjects is to repeat the affect (as experiential benefit) stemming from being consumed by abjects.

Abjection is a dimension of human experience that is based on affect, rather than reason. It is a negative feeling, not a rational law. An individual's dislikes in food will have an abject basis (Lechte, 2003, p. 10).

This overwhelming affect, as jouissance consumption, constitutes a conditio sine qua non of their very existence and not a peripheral aspect of their consumptive habits.

Jouissance alone causes the abject to exist as such. One does not know it, one does not desire it, one joys in it [on enjouit]. Violently and painfully. A passion (Kristeva, 1982, p. 9).

In the context of abjective consumption, products as objects for jouissance either are meaningless in the first place, or they become meaningless while being dislocated from their conventional, symbolic contours. Although this conceptual pillar will be further 
elaborated in the empirical illustration of abjective consumption, it merits stressing at this juncture that eating dirt or cigarette ash as abjects (cases 15 and 35 respectively in our corpus; cf. Appendix, Table AI) constitute remarkable examples of deriving jouissance from consuming meaningless "objects". Such "objects" are meaningless insofar as they constitute mere waste, dislocated from any system of relevances whereby signs assume meaning and value through relations of inter-dependence. "According to Lacan, the meaninglessness of abjects results ultimately from the meaninglessness of nature, matter, and the physical realm" (Berressem, 2007, p. 46). As regards the second sub-type of meaninglessness, products that carry symbolic attributes and convey symbolic benefits in the symbolic order (e.g. cheeseburgers), in the context of abjective consumption become dislocated from their customary symbolic contours, while being reduced to instantiations of abjects as material ground for deriving jouissance. The convention (its "cultural code" pace Schroeder, 2009) that sustains a sign symbolically constitutes at the same time a taboo (Rossolatos and Hogg, 2013) that marks a prohibition against the transgression of a product's interpretively binding status. "To transgress a taboo produces revulsion and a feeling of abjection" (Lechte, 2003, p. 11). The abjective consumer is not a brand loyal customer, insofar as he does not subscribe to a brand-related image inventory, but a fan of that dangerously gaping black hole, the khoric realm.

Finally, in conjunction with the dislocation of products from their customary symbolic contours and cultural axiological frameworks, the abjective subject experiences a dissolution of selfhood by dint of his uncontrollable habit being misaligned with cultural expectancies (as provisionally granted sense of "normalcy" or Freudian "reality principle") and the constant need for maintaining secrecy as regards his transgressive habit from significant others (friends, family). Abjects "introduce a fundamental ambiguity and ambivalence into the subject's world that threatens it in its very constitution as a coherent psychic aggregate" (Berressem, 2007, p. 23). Most importantly, on several occasions abjective consumption is coupled with hazardous health effects. Despite becoming cognizant of such effects, the abjective consumer persists more often than not in his compulsive behavior. Because of jouissance being experienced as a mixed effect of pleasure and pain, the latter is usually confronted with denial by the abjective consumer (repudiation, in Kristeva's (1982) terms, also carried over to Butler's (1993) vocabulary).

The abjection of self would be the culminating form of that experience of the subject to which it is revealed that all its objects are based merely on the inaugural loss that laid the foundations of its own being (Kristeva, 1982, p. 6).

What is lost is not an object that might be found, but the milieu of the khoric space as such. The subject has been severed from this milieu precisely to avoid paradoxically the lapsus mortalis as loss within the khoric continent. It is a vital loss in the face of the otherwise imminent death/dissolution of the ego. This dissolution that is carried over in repetitive consumptive acts as slow decay and cadaverous becoming (broken teeth because of chewing dirt, skin decay because of washing up with bleach; cases 15 and 38 in our corpus, respectively).

Having, thus far, outlined the conceptual framework for understanding how abjective consumption is evinced, the analytical focus now turns to examining how abjective consumption actually surfaces in concrete social situations by drawing on Goffman's frame theory (Goffman, 1974), in the context of the mediatized portrayal of abjection cases. But first, a short detour into how central Goffmanian concepts have been applied thus far in consumer cultural research, spanning his entire intellectual output, is instrumental for anchoring this study more concretely in the light of antecedents.
Framework of abjective consumption 
QMR 21,1
Antecedents to adapting Goffmanian concepts in consumer cultural research A string of key Goffmanian concepts, such as self-presentation in public places, the dramaturgical metaphor, stigma, framing and social situation, ritual, have been multifariously operationalized by consumer researchers. Self-presentation strategies have been addressed in the context of managing situated self image (Schenk and Holman, 1980), the construction of identity in fashion blogs (Kretz, 2010), Facebook (Mimoun and Ammar, 2013), youtube (Chen, 2013), but also in examining how a sense of selfhood is extended in intangible game avatars and virtual possessions in online games (Nguyen et al., 2011). The dramaturgical metaphor has been recruited in addressing the disposition of possessions during role transitions (Young, 1991) and women's descriptions of their deteriorating service relationships (Ligas and Coulter, 2001). Furthermore, attempts have been made at furnishing a typological framework of territorial behavior and rudeness in social interaction (Griffiths and Gilly, 2009) by drawing on Goffman's insights on relations in public places. In addition, the derivative concept of encroachment was recruited by Banister et al. (2005) in their exploratory research into second-hand clothing purchase and wearing motivations and perceptions. Holt (1992) draws on Goffman's conceptualization of everyday rituals as performances that more often than not harbor personal motives, far removed from any quest for authentic or sacred experiences, to challenge the dialectic between sacred/profane in which cultural practices are often couched in consumer research. The concept of social situation that is central to Goffman's (1974) frame theory was drawn upon by Woermann and Kirschner (2015) while examining how the content of the live-streaming site Dota2 was co-created by its members. Most relevant for the study at hand in terms of research orientation is the ethnographic exploration of the freegan community by Nguyen $e t$ al. (2011). In this context, the authors identified a new strategy for coping with practices such as dumpster diving which they tagged as counter-stigma. Thus, over and above Goffmaninspired consumer research on stigmatization which assumes that the stigmatized individual acknowledges his or her discredited status (Veer, 2009) and the de-stigmatization that occurs when a stigmatized practice gets naturalized or erased through routine exposure over time (Sandickc1 and Ger, 2010), "counter-stigma" occurs whenever the stigma of waste (fullness) is re-directed onto the mainstream consumer culture. In other words, the process of de-stigmatization, again from a Goffmanian point of view, concerns the reframing or axiological transformation of a negative experience (viewed as such by mainstream culture) into a positive one (viewed as such by the members of the stigmatized community) against the background of their "niche" moral system that rebukes wasting as against salvaging food from waste-bins. This reframing has important social implications as it mitigates the probative force of disavowal in the face of conflicting, yet equally valid moral systems. Moreover, Kang et al. (2013) addressed stigmatization in the light of evasive strategies followed by consumers to circumvent potential disclosures of ego-threatening information, such as having paid higher than expected prices in the acquisition of goods. A similar research orientation was pursued by Saatcioglu and Ozanne (2010) in their study of how individuals manage stigma across contexts.

\section{The principles of Goffman's frame analysis}

According to Goffman's micro-sociological perspective (which he struggled to differentiate from symbolic interactionism, especially in the absence of a coherent conceptual edifice), every social phenomenon constitutes a social situation that is framed in various manners by the involved social actors. The influence of Goffman's frame theory (alongside his dramaturgical metaphor) on disciplines such as organizational behavior (Bolman and Deal, 2003) has been 
paramount. According to Goffman, meaning emerges in concrete experiences as social situations, rather than being determined by the ontological status of objects.

Abjective consumption takes place in specific social settings and involves discrete types of social actors who perform different roles in framing this social situation. The principles of frame analysis may be summarized as follows. Framing, according to Goffman (1974, p. 11), concerns the articulation of experience, and hence refers to a purely discursive construal (linguistic and multimodal) of social situations. This construal is dependent on situated social actors' interpretive schemas (Goffman, 1981, p. 68) as the outcome of ongoing enculturation. Social situations may be segmented into what Goffman called "strips" (equivalent to what in filmic analysis is usually conceived of as "shot" or "sequence"), that is:

[...] arbitrary slices or cuts from the stream of ongoing activity, including here sequences of happenings, real or fictive, as seen from the perspective of those subjectively involved in sustaining an interest in them (Goffman, 1974, p. 10).

Of particular importance in framing social situations is the concept of "key", that is the set of conventions by which a given activity is transformed into a pattern of sequences. As already shown, Goffman's "key" is equivalent to "code" in semiotic theory and "cultural code" in consumer cultural research. Insofar as social conventions that allow for recognizing strips as recurrent slices of life that make up particular social situations rest at a tacit level in communicative interactions among social actors, the researcher is burdened with the onerous task of rendering these conventions explicit. Conventions constitute background expectancies as tacit rules for the enactment of social situations. This task is facilitating visà-vis the underlying objective of pointing to fissures in the seeming integrity of a cultural web, as Freudian reality principle, where abjective consumption emerges most strikingly. These fissures in the cultural web, as we shall see in the ensuing section, are experienced as clashes between different frames that are experienced through different and co-existing orders of discourse, most broadly between the frame of abjection that does not abide by symbolic conventions and the rest frames that are subsumable under symbolic and conventionalized social interaction (moralizing frame, medical frame etc.). In addition, fissures are experienced as a disruption of the "tie-signs" that are used by social actors to mark their relationship (Goffman, 1971), such as walking hand in hand in public, exchanging expressions of involvement during sexual intercourse and engaging in everyday rituals (Goffman, 1967, 1971, p. 199). The more conventionalized a social situation, the more it is expected to be enacted in a ritualistic form, that is by following a prescribed social syntax (e.g. the ritual of brushing one's teeth).

Subsequently, in the following Sections I draw on a corpus of 50 episodes from the series "Freaky Eaters" and "My Strange Addiction" that include remarkable cases of abjective consumption, with a view to demonstrating, in line with our conceptual pillars, what sort of abjects are consumed, how irrationality seethes into the purchase and use of abjects, what types of meaninglessness are involved, as well as how the self dissolves in the face of abjective consumption. Each of the analyzed episodes is segmented into the frames whereby abjective consumption is negotiated by distinctive types of social actors, while noticing how the frame of abjective consumption clashes with the rest frames in terms of conventions as background cultural expectancies.

\section{Research design}

A qualitative research design was adopted in this study, informed by ethnographic research practices and protocols, as follows:
Framework of abjective consumption 
QMR 21,1

\section{8}

Data collection

A sample of $\mathrm{N}=50$ individual episodes from two popular TV series, "Freaky Eaters" and "My Strange Addiction" (aired between 2010-2011 and 2010-2012 respectively on TLC in the USA) was put together, each episode constituting a distinctive sampling point (Miles and Huberman, 1994). "Unlike Garfinkel, Goffman set the situation and not the actor or individual consciousness as the basic unit of analysis" (Heiskala, 1999, p. 230). The content of these series which is presented in documentary form constitutes fertile soil for exemplifying the offered conceptual framework of abjective consumption, as the episodes present real-life cases of people with bizarre addictions to food and/or eating disorders (according to the series' official description). "Video analysis in the social sciences can be considered as a kind of ethnography using video, to be more exact: a videography" (Knoblauch, 2012, pp. 69-70); "as the method to analyse people acting in social settings by video" (p. 71). "Ethnographic applications of both photography and film employ a broadly documentary approach" (Ball and Smith, 2007, p. 305).

\section{Sampling}

The sample was sourced in its totality from youtube, while ancillary information about the shows hosted on TLC's website was also drawn upon as background literature. Using readily available audiovisual materials on popular social media as analytical groundwork constitutes standard practice in netnography (or online ethnography), videography, archival data research, qualitative sociological inquiry and semiotic analysis. Although some degree of bias is bound to be inherent in these data because of their pre-recorded status, they are particularly useful, as this is a "difficult sample" in qualitative methodological terms. Drawing on a sample of secondary audiovisual data is not commensurate to the scope and depth of questions and the investigative methods (e.g. phenomenological interview, consumer diaries, projective techniques) that could be adopted in the context of a bespoke sample. However, given that the concerned group constitutes a difficult sample, unless the researcher already operates in a clinical context, and given that the audiovisual data were used for exemplification rather than confirmatory purposes, the sample profile is deemed to be both pertinent and sufficiently informative. Hence, the benefits outweigh the potential limitations of this sample. In any case, as is well-known, even primary audiovisual field data are not bereft of selectivity (Dicks et al., 2006). Furthermore, as noted by Miles and Huberman (1994), the greater the analytical depth that is required of interviewees, the smaller samples tend to be used. In this study, it was particularly important to use as many cases as possible to identify whether and how the outlined conceptual pillars of abjective consumption do in fact recur across individual cases.

\section{Data analysis}

Prior to proceeding with the actual analysis, I watched the episodes featured in the corpus several times to obtain a primary feel for the data, to familiarize myself with the involved actors, abjects, settings, but also to obtain the requisite pre-understanding (Wägar, 2012) that would enable me later on to engage self-reflexively in the analysis. As a second step in field research, I watched each documentary in greater detail, while taking fieldnotes in the same fashion as performed in "natural" settings (Emerson et al., 2007). I adopted a selfreflexive mindframe while taking notes, trying to remain as distanced as possible from the deploying narratives as regards personal axiological judgments. At the same time, I did notice on several occasions, and this should be taken into consideration, that although the episodes were allegedly composed in documentary form, they were not utterly bereft of dramaturgy, insofar as both the directly affected by abjective consumption subjects, as well 
as the indirectly affected significant others re-enacted, that is performed in the context of the documentaries' exigencies, their direct experience of and responses to abjective consumption that may have taken place in the remote past. The dramaturgical aspect of the documentaries is further compounded by the production and post-production techniques (editing) that mitigate the social realistic character of the episodes, as salient facets become technologically manipulated, resulting in channeling the meaning of the portrayed experiences toward pre-planned directions. Taking account of the staging of the documentaries also turned out to be a pre-requisite in correctly framing the portrayed social situations. On the other hand, by dint of conducting research on recorded data, rather than being immersed in actual observational settings without the ability to record, yields the comparative advantage of being capable of playing back different scenes. Moreover, it allows for engaging constantly in comparative and iterative evaluations between data and fieldnotes in line with the constant comparative method, thus importing both etic and emic outlooks in the analysis (Goulding, 2005).

It is likely that the principal data, the recordings, will be reviewed a number of times during the course of the project, where each of those reviews will be focused in rather different ways (Heath et al., 2010, p. 62).

Although a grounded theoretic approach was not adopted in this study, as theory building was not the main objective, as against illustrating the offered conceptual framework by recourse to relevant documentaries, an open/axial coding procedure was followed in part with regard to details that could not be determined a priori, as against their general superordinate categories. For example, although significant others, frames, keys and social situations were indispensable conceptual aspects of each case's makeover, no detailed account could be offered as to specific sub-types prior to conducting the fieldwork. For the sake of systematically recording these details, an Excel matrix was used, in line with customary videography/video ethnographic analysis practices (Dey, 2010; Heath et al., 2010; Knoblauch, 2012), with individual cases in rows and the key pillars of the conceptual framework of abjective consumption, as well as the key concepts for framing social situations, in columns.

Finally, the need for addressing contextual aspects in any documentary hermeneutic procedure (Pollak, 2008), spanning both co-textual (that is directly contextual or intra-filmic) as well as broader inter-textual and social institutional facets, was taken on board. Subsequently, the analysis took into consideration the impact of production techniques, as well as how invited experts (e.g. physicians) contributed to framing the meaning of abjection.

\section{Data synthesis}

In line with ethnographic protocols on setting up, conducting and writing-up the results of a survey, the synthesis phase consisted of the report write-up based on the fieldnotes taken while watching the documentaries, as well as on the memos that were annotated on the field notes. The data were ultimately synthesized in a quest for pattern generation alongside the conceptual pillars of abjective consumption, as well as the salient facets of the experience of abjective consumption in discrete social situations, as follows:

(1) Abject/Fetish/Other (A/F/O)

- A: The concerned object constitutes an abject consumed according to the frame of abjective consumption, that is (i) experienced as part of jouissance consumption for the direct consumer, while (ii) transgressing the symbolic contours of this product (iii) perceived as "disgusting" by significant others
Framework of abjective consumption 
QMR 21,1

Table I.

Abjective consumption cases (iv) transgressing a "key" (convention) of a social situation, thus disrupting the expected enactment of a daily ritual.

- Only cases of abjection were used in the discussion of findings section (as per Table I). Twenty-three cases of abjective consumption were singled out from the entire corpus, 18 "other" cases and 9 fetish cases.

- F: The concerned object is not an abject, but a fetish, that is (i) still overcathected by the direct consumer, albeit not (ii) causing disgust on behalf of significant others. For example, in the case of "Ken the Living Doll", the concerned social actor fetishized Barbie's companion to such an extent as to actually wish to become him. There is nothing abjective in this consumptive desire that constitutes a different way of meeting one's ego-ideal in the form of a beauty-ideal, especially given contextual biographic information of this actor that clearly informs us about his childhood dream of joining the jet-set and being surrounded by beautiful people. This is a striking incidence of how the ascription of the term "addiction" to markedly distinctive types of cases merely affords to obfuscate massive underlying differences (which is justifiable given that the objective behind airing these documentaries was not academic research, but revenues for a commercial TV channel).

- O: The concerned object is neither an abject, nor a fetish, but another sort of compulsive consumption behavior, mainly because of the exceedingly above average volume and/or frequency or both whereby it is consumed, yet within the conventional, symbolic contours of the product, while not necessarily

\begin{tabular}{rll}
\hline Case ID's & Addiction (as per documentary's description) & Abject/Fetish/Other (A/F/O) \\
\hline $3^{*}$ & Eating couch cushions & $\mathrm{A}$ \\
4 & Eating plastic bags & $\mathrm{A}$ \\
6 & Eating sand & $\mathrm{A}$ \\
7 & Eating vapor & $\mathrm{A}$ \\
8 & Eating plastic & $\mathrm{A}$ \\
9 & Eating spay & $\mathrm{A}$ \\
13 & Eating only soft pretzels & $\mathrm{A}$ \\
14 & Eating rocks for dinner & $\mathrm{A}$ \\
15 & Crunching on dirt & $\mathrm{A}$ \\
16 & Eating from a dumpster & $\mathrm{A}$ \\
17 & Mothball sniffing & $\mathrm{A}$ \\
18 & Eating household cleaner & $\mathrm{A}$ \\
19 & Drinking urine & $\mathrm{A}$ \\
33 & Eating hair follicles & $\mathrm{A}$ \\
35 & Eating cigarette ashes & $\mathrm{A}$ \\
36 & Eating glass & $\mathrm{A}$ \\
38 & Skin bleaching & $\mathrm{A}$ \\
40 & Compulsive scab picking & $\mathrm{A}$ \\
41 & Eating cat food & $\mathrm{A}$ \\
43 & Hairless rat love & $\mathrm{A}$ \\
44 & Huffing gasoline & $\mathrm{A}$ \\
45 & Eating toilet paper & $\mathrm{A}$ \\
46 & Taxidermy addict & $\mathrm{A}$
\end{tabular}

Note: *Numbers in the first column correspond to the case ID's as per Appendix, Table AI 
being perceived as disgusting by significant others. For example, eating a truck-load of cheese-burgers within a year not only does not transgress the symbolic contours and the cultural value of a cheeseburger (at least for the consumer segments that hold this category in esteem), but constitutes an extreme case of at least product (if not brand) loyalty.

(2) Short description of abjective consumption (what, when, how, how much).

(3) Social situations affected by abjective consumption as fissure in the cultural web (e.g. work, family, after-work entertainment).

Framework of abjective consumption

(4) Discursive order whereby abjection is framed by the direct consumer of abjects.

(5) Discursive order(s) whereby abjection is framed by significant others- indirectly affected by abjective consumption.

(6) Affective reaction of significant others upon being informed about the direct consumer's abjective consumption.

(7) Convention that is transgressed, thus giving rise to significant others' affective reaction.

(8) Irrationality.

(9) Meaninglessness.

(10) Dissolution of selfhood.

(11) Other notes.

\section{Framing abjective consumption in the documentary TV series "My Strange Addiction" and "Freaky Eaters"}

The portrayal of "addictions" in the course of each "My Strange Addiction" documentary follows an almost identical pattern. Initially, the documentary's logo appears on screen, quite remarkably in the form of a polar attractor inside a "black hole" toward which various pieces from the periphery of the screen are drawn as if by a magnet, thus simulating the irrational attraction experienced by subjects in the face of the abject. The abject lies "opposite the I" as a khoric space around which all the other aspects of an abjective consumer's life narrative are drawn and into which the subject withdraws. Moreover, even more strikingly, on the right and left hand sides of this massive gaping hole lie two X's. For Lacan, the $X$ was used to point to the unsymbolizable excess of the Real (Homer, 2005). The transition of the different frames making up this addictive "black hole" shot is enacted against the background of a jingle that is very closely reminiscent of the X-Files opening theme, thus affording to invest the documentary inter-textually with the properties of mystery, horror, dark secrets. Straight after the opening card we see each episode's main actor, that is the abject's consumer, stating hihe/sher name, place of residence, age and finally what he/she is "addicted to". The presentation of self (Goffman, 1959) in front of the camera in this establishing shot is enacted in a manner akin to introducing oneself in an alcoholics anonymous community, and, moreover, by having framed a priori abjective consumption in terms of an "addiction". Immediately thereafter follows a detailed description of how the abject is consumed, either by the subject herself or by an impersonal narrator. This description is succeeded by commentaries about thoughts and feelings stemming from abjective consumption for the direct consumer and for those significant others who are indirectly affected by abjective consumption by dint of being related to the direct consumer. Then, significant others (friends, family) and occasionally a "scientific expert" (physician) comment on the subject's abjective consumption. The documentary 
QMR 21,1

occasionally ends with a message that is intent on restoring "normalcy". With slight variations, the above summarize the usual flow of sequences making up the experience of abjective consumption. A closer look at each of the territories whereby the social situation of abjective consumption is articulated will aid in identifying instances that are illustrative of the conceptual pillars that buttress it.

Starting with the abjection pillars, in the majority of cases all three were found to be operative. Irrationality was evinced uniformly across the entire corpus of abjects in the form of jouissance consumption, where the pleasure derived from consuming abjects was explicitly recognized by the consuming subjects as overriding any adverse, painful sideeffects: "it's totally scorching the eye-lids, but it's a good burn" (7 [numbers in parentheses correspond to the individual cases of Table I] - eating vapor); "different sort of pain in nose and eyes while pouring urine" (19 - drinking her own urine); "it sounds awful in my head, the actual chewing, but I enjoy this a whole lot" (36 - eating glass); "If I feel pain when I do this, I feel I'm doing the job right" (40 - compulsive scab picking). Jouissance consumption is coupled either with the utter absence of a rational calculus whereby benefits are weighed against expenses, or with the provision of pseudo-rationalizations. The absence of rational calculation is evinced quite strikingly in case 44, where the subject who is drawn to huffing gasoline, although unemployed, admits to rather spending on gasoline than food, or in case 43 where the subject who is in a similar socioeconomic situation always ensures first and foremost that her rats are adequately fed, despite having received an eviction to clear her property.

Meaninglessness emerges in the majority of cases either as dislocation of the consumed products from their symbolic contours and their reduction to pure materiality (pace Lacan), or in the affective over-investment of waste. As regards the former, examples from our corpus abound: eating couch cushions (3), eating plastic bags (4), eating vapor (7), reducing remote controls and cocktail swords to edible plastic (8), eating household cleaner (18). To a similar extent, we encounter representative examples of the latter in: eating cigarette ashes (35), eating hair follicles (33), eating sand (6), rocks (14), dirt (15) and drinking urine (19). It should also be mentioned that in the majority of cases where abject consumers are requested to provide reasons for their abjective consumption, they usually reply by highlighting the abjects' tangible properties (e.g. taste, texture, smell, crunchiness). These reasons constitute pseudo-rationalizations and under-determining consumption drivers, as the same effects could be garnered by a myriad substitute products, without the devastating side-effects. This tendency to treat abjects as objects and to de-stigmatize a transgressive consumption habit is an attestation of the workings of primal repression whereby the need for consuming abjects may only surface rationally as a symbolically acceptable "reason-why".

Complementary to such "rational rationalizations" we encounter "irrational rationalizations", such as attempts to justify an abjection habit to non-abject consumers by drawing untenable parallels between consuming cat-food (41) and taking in (just like a cat would) the vitamins that are mentioned on the pack or "if I eat in a restaurant I don't know who's preparing the food back there, so I feel like it's in a way cleaner from a dumpster" (16). Quite astonishingly, as remarked by Derrida in his monograph on Khora (Derrida, 1992), it is only through false reasoning (notho logismo, Gr.) that this space is accessible. Again, this false reasoning is not a case of disavowal (or being in denial), but a recognition that the "object" of abjective consumption is by definition divested from any reason-why, expropriated into absolute exteriority. But also, the interpretive clash between abject consumers' rationalizations in an attempt to latch onto the symbolic order and the "dark side" of their choices that is unearthed through the offered psychoanalytic reading in an attempt to demonstrate how the order of the 
Real shows through abjective consumption, opens up a liminal space for thoughtful criticism of ethnographic methodological orthodoxies, such as the ability to see the world through consumers' own eyes and the recurrent allusion to Weberian empathy (verstehen) (Elliott and Jankel-Elliott, 2003). Certainly first order articulated meaning on behalf of consumers is a necessary condition for framing a market phenomenon, but by no means sufficient in a standalone fashion for effecting closure, especially where difficult cases such as abjective consumption are at stake.

Loss of selfhood as an unconditional giving in to the abject and overwhelming overtaking by the abjective consumption affect are evinced quite strikingly in the subjects' verbatims, but also in their inability to control the devastating effects in terms of harmful physical side-effects and the social situations that are disrupted as irreparable fissures in their cultural web. "I wouldn't be able to function every day if I did not eat some quantity of rock" (14); abjective consumer (13) eating pretzels while having sex with his girlfriend, but also hitting her hard in the face for hiding his pretzels; spending US $\$ 20,000$ on teeth work, two lost teeth, teeth grinding (15), coupled with the pseudo-rationalization "rather than stop, I can use stronger teeth and by picking up better quality dirt"; in the light of receiving information about the possibility of kidney failure from a physician, the urine drinker gets round it by questioning the doctor's knowledgability as regards this alternative form of treatment. The hair follicles eater dropped out of high school because she couldn't learn, think and concentrate, while the bleach drinker has ruined her clothes and damaged her furniture. The spray eater's fiancé is particularly disturbed whenever his companion asks for a kiss once having consumed spray. In Goffmanian terms, and with regard to the social implications of abjective consumption, we notice an irreparable disruption of everyday rituals resulting in the alienation of significant others from the abjective consumer, as the outcome of disrupting the integrity of tie-signs (hiding pretzels, kissing with mouthful of spray). Moreover, we witness the progressive alienation of the abjective consumer from social situations prescribed in formal and informal institutions (dropping out of school because of eating hair follicles; stopping inviting friends because of damaged furniture; damaged clothing because of over-bleaching).

As regards the ways whereby abjective consumption was framed by:

(1) the direct consumers;

(2) significant others (friends, family); and

(3) doctors, again, we notice a clear and repetitively so pattern that is affirmative of the different affects by the involved groups as outlined earlier.

The difference in affective formations and framings of abjective consumption between (1) and (2) has already been identified as an area that may expand our understanding of this phenomenon vis-à-vis the unilateral focus on disgust by Kristeva (1982). As regards the abjects' consumers, they all experience abjective consumption as a positive, life-affirmative experience, without an inkling of disgust or repulsion. We encounter exactly the opposite scenario uniformly in significant others' treatment of abjection: "It's nasty, it's disgusting, but she loves it and I love her, so I'll have to deal with it" (9, friend), "that's crazy, nasty" (6, sister), "it's a little weird" (4, fiancé), "Repulsive smell: It makes the house smell really nasty, it's gross" (7, daughter). "I don't know how she actually came to crave ashes; it' disgusting" (35). Disgust emerges as a defensive symptom on behalf of individuals not prone to abjective consumption, that is as a mechanism for maintaining the integrity of a cultural web by exorcizing affectively the abject (which functions at the same time as the suppressed underpinning of culture by virtue of demarcating $a b$ inverso the boundaries of
Framework of abjective consumption 
QMR 21,1

the "inside"). What is blatantly absent from the abjection related literarure is that for those prone to abjective consumption, abjects are consumed as parts of positive, rather than negative experiences. Subsequently, we are forced to re-evaluate the ascription of pure and unconditional negativity to abjects in the light of their being experienced as positive and existentially affirmative moments: drinking urine, for example, does not maintain the khoric realm at a distance, while upholding through disgust the frail balance between outside and inside, but is evinced as unconditional giving into, as recurrent existential need.

It is a "defensive symptom" vis-a-vis the very nature to which, owing to its connection with the "lower" and "more obscure senses", it has often been ascribed. Like all other such symptoms, the defensive symptom of disgust is a compromise formation: it not only testifies to the power of repression but, in the mode of conversion, it also brings the repressed impulses to a negative presentation (Menninghaus, 2003, p. 190)

On an equal footing, we encounter a latent wish for turning "inside/out", literally as regards bodily innards, in abject consumers' narratives: "there's a very distinct possibility it could be cutting deep down in my body" (36). "I cut open a few layers of skin just to have more scabs to pick" (40). "that's a gross thing to be doing" (46). Contrary to "normal" subjects, the abjective subjects respond with nauseating disgust not in the face of abjects, but of invitations to consume "normal" products: throwing up at the prospect of eating a carrot instead of a pretzel (13).

Further to considering how abjective consumption is framed as a positive experience by their direct consumers and as disgusting by significant others, it merits dwelling for a while on what I call the moralizing frame, as put forward indirectly by the show's producers in the context of the employed production techniques and the way whereby abjection is presented.

First, it becomes manifest that the radical alterity of the abject is reduced through this frame to a manageable media representation, while the medium expands its legitimating and ethotic capacity to the farthest corners of a cultural edifice. This cultural frontier is synonymous with the object of primal repression which is now appropriated as an audience's structural unconscious. Most strikingly, though, emerges the manner whereby the meaning of abjects is negotiated through their mediat(izat)ion, that is through an unseen probing of their consumers into the "whys" of the abjects' consumption. Hence, abjects through a process of mediatized rationalization are "domesticated" from their ontological wilderness and reduced to sets of properties, assimilable to market-ready products. Their alien aura, thus, recedes in the advent of their domestication in the media spectacle. The khoric (third realm) dimension of the abject (Kristeva, 1982) is reintegrated into a panoptically assimilating media dialectic between the inside/outside. The giving in of the subject's body to absolute exteriority is reintegrated into the space of culture (respaced), it becomes enculturated and, hence, domesticated.

The second point concerns the role performed by others (and particularly rejecters of abjects) in the orchestrated spectacle of abjects' consumption. These are most often kins or close friends of abjects' consumers. They are informed about their peers' transgressive consumption ethos in a manner that is akin to a confession, tinged with almost criminal overtones, like breaking a taboo at the moment the non-communicable and ineffable abject enters an interpellative dialectic. Most importantly, the "authority" to whom the subject's transgressive act is imparted is not an impersonal institutional agency, but a community member, thus shifting responsibility for conferring judgments on legitimacy criteria to lay social actors in the context of autopoetically forming social constellations.

Third, and with regard to the mode of production of the abjection spectacle, the act of consumption per se is repeated several times over the course of an episode, thus simulating the repetitively compulsive manner whereby abjects are regularly consumed, accentuated 
through close-ups, slow-motion and different angles. The reason being not merely that the cultural and health-related hazards must be communicated as emphatically as possible, but that the spectacle must be communicated with as great transparency as possible.

In conclusion, it should be highlighted that the reason why it is impossible, or, at least, considerably painstaking to establish communicative bridges between abjects' consumers and the rest stakeholders in the social situation of abjective consumption, lies in that each social group frames this phenomenon in completely different ways as regards the frame's relationship to each of the three Lacanian orders. In the beginning of my exposition I tried to make as clear as possible that the abject, far from being equivalent to an object, creates a rapport between the consuming subject and the order of the Real, whence stems the reduction of products to pure materiality, regardless of their normative function in the Symbolic order. Halfway between the order of the Real as absolute exteriority that is experienced affectively by the consuming subject in the in-betweeness of jouissance consumption (the pleasure that interiorizes and the pain that repels toward the outside at the same time) and the order of the Imaginary whereby the subject negotiates novel, nonsymbolic properties for its abject (the taste of a household cleaner) lies the "truth" of abjective consumption. On the antipode of this rapport of the abject's subject lie the frames espoused by the documentary's producers, the physicians and the significant others whose articulations of the abjection phenomenon are constrained in the symbolic order (cf. Table II). Their rapport with the abject's consumer is edified solely in terms of the symbolic order, in utter disregard of the actual order on which the abject's subject operates while giving into the need for and the demand issued by the abject. Thus, quite disproportionately, when the former stakeholders seek to "cure" the abject's subject of its uncontrollable need, they merely perpetuate the cardinal sin of failing to discern the wholly different order on which abjective consumption operates.

In conclusion, a key benefit that may be reaped from following the psychoanalytic interpretive route that was deployed in this paper, inasmuch as consumer psychoanalytic approaches to consumer behavior in general, consists of its marked ability to comprehend the differential impact of addressing consumptive phenomena on different orders at the same time.

\section{Conclusions}

The primary purpose of this paper was to furnish an inaugural reading of the abjective consumption phenomenon. To this end, a conceptual framework was put forward against the three pillars of irrationality, meaninglessness and dissolution of self, while contextualizing the psychoanalytic construct of abjection within the broader consumer cultural research terrain. The conceptual pillars were further refined through the exemplification of the framework by recourse to an empirical study of abjective consumption cases. A qualitative research design was used for the empirical prong by using principles and protocols of ethnographic documentary research. The

\begin{tabular}{|c|c|c|c|}
\hline $\begin{array}{l}\text { Orders } \\
\text { Frames }\end{array}$ & Real & Imaginary & $\begin{array}{l}\text { Symbolic } \\
\text { Social groups }\end{array}$ \\
\hline
\end{tabular}

Abjective (jouissance) frame

Medical frame

Moralizing frame

Suffering frame
Abject consumers

Physicians'

Documentary Producers

Significant others (friends, family)

Framework of abjective consumption

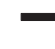


QMR 21,1

documentary cases on which the illustrative analysis drew were illuminating as to the potency of the offered psychoanalytically informed framework to cut through orthodoxies embedded in time-hallowed perspectives, such as symbolic and hedonic consumption and to offer a nuanced outlook to an allegedly obscure consumptive phenomenon. At the same time, the limitations in distilling the "meaning" of this consumptive phenomenon by taking at face value consumers' symbolic representations emerged quite forcefully, while attending closely to how abjective consumption is framed differentially by distinctive consumer groups. This is a particularly salient area for consumer research at large that points at the same time to the unique contributions of a consumer psychoanalytic perspective. By attending narrowly to how the same phenomenon functions and may be framed by recourse to the three Lacanian orders, we can appreciate the inherently multifaceted nature of social and psychological phenomena. This appreciation has important repercussions both for those who are directly involved in abjective consumption cases, as well as for the various stakeholders with whom they interact in various manners. On the one hand, by addressing abjective consumption at the order of the Real, direct consumers of abjects are exculpated from the pathologizing contours of the Symbolic order which is the province of behavioral and ego-centric psychological perspectives. On the other hand, the adoption of a consumer psychoanalytic perspective allows significant others to fully dimensionalize the behavior of abjective consumption subjects, by becoming sensitive to other than symbolic and even imaginary aspects that are endemic in consumer behavior. This multi-order dimensionalization also opens up new vistas to marketers in terms of adding novel dimensions to the message structure of their communicative programs, in line with the three Lacanian orders. In addition, it adds a nuanced interpretive layer to what might be perceived as brand loyal consumer behavior, by drawing a sharp distinction between consumer loyalty (and even inertia) and abjective consumption.

On a methodological level, this study contributes to the constantly expanding consumer ethnographic literature by adopting a nuanced documentary ethnographic approach against the background of audiovisual data, while recognizing the limitations of readily available secondary data and weighing their benefits against their limitations.

Finally, as regards opportunities for further research, abjective consumption constitutes a ubiquitous phenomenon that has not been conceptualized until now. Going forward, there are significant opportunities in terms of pursuing further contrastive readings vis-à-vis fetishism (which was undertaken in a sketchy fashion in this paper), ego-centric behaviorist perspectives, different consumptive occasions, fandom and compulsive purchase and usage habits for various product categories. On a methodological level, there is significant scope for adding greater informational depth by conducting long phenomenological interviews with smaller samples (1-5 informants), but also to engage ethnographically in participant observation with a view to multiplying the frames whereby abjective consumption is filtered by situated social actors.

\section{References}

Arnould, E.J. and Thompson, C.J. (2005), “Consumer culture theory (CCT): twenty years of research”, Journal of Consumer Research, Vol. 31 No. 4, pp. 868-882.

Askegaard, S. and Trolle Linnet, J. (2011), "Towards an epistemology of consumer culture theory: phenomenology and the context of context”, Marketing Theory, Vol. 11 No. 4, pp. 381-404. 
Banister, E.N., Hogg, M.K., Decrop, A. and Roux, D. (2005), "Clothes make the man: symbolic consumption and second hand clothing", in Ekstrom, K.M. and Brembeck, H. (Eds), European Advances in Consumer Research Volume 7, Association for Consumer Research, Goteborg, pp. 455-456.

Bauman, Z. (2007), Consuming Life, Polity, Cambridge, MA.

Baumgartner, H. and Pieters, R. (2008), "Goal-directed consumer behavior: motivation, volition, and affect", in Haugtvedt, C.P., Herr, P.M. and Kardes F.R. (Eds), The Handbook of Consumer Psychology, LEA, New York, NY, pp. 367-392.

Berressem, H. (2007), "On the matter of abjection”, in Kutzbach, K. and Mueller, M. (Eds), The Abject of Desire: The Aestheticization of the Unaesthetic in Contemporary Literature and Culture, Rodopi, Amsterdam, pp. 19-48.

Ball, M. and Smith, G. (2007), "Technologies of realism? Ethnographic uses of photography and film", in Atkinson, P., Coffey, A., Delamont, S., Lofland, J. and Lofland, L. (Eds), Handbook of Ethnography, Sage, London, pp. 302-320.

Bolman, L.G. and Deal, T.E. (2003), Reframing Organizations, Jossey Bass, San Francisco, CA.

Butler, J. (1993), Bodies That Matter, Routledge, New York, NY.

Caslav, C.D. (2004), Amending the Abject Body: Aesthetic Makeovers in Medicine and Culture, SUNY, New York, NY.

Chanter, T. (2008), The Picture of Abjection: Film, Fetish and the Nature of Difference, Indiana University Press, Indianapolis.

Chen, C.P. (2013), "Digital self and parasocial interaction on Youtube", in Cornelissen, G., Reutskaja, E. and Duluth, A.V. (Eds), European Advances in Consumer Research Volume 10, Association for Consumer Research, Minneapolis, pp. 126-127.

Derrida, J. (1992), Khora, Galilee, Paris.

Dey, I. (2010), Qualitative Data Analysis: A User-Friendly Guide for Social Scientists, Routledge, London.

Dicks, B., Soyinka, B. and Coffey, A. (2006), "Multimodal ethnography", Qualitative Research, Vol. 6 No. 1, pp. 77-96.

Dor, J. and Gurewich, J.F. (2010), Introduction to the Reading of Lacan: The Unconscious Structured like a Language, Other Press, London.

Eco, U. (1975), Theory of Semiotics, Indiana University Press, Indianapolis.

Elliott, R. (1997), "Existential consumption and irrational desire", European Journal of Marketing, Vol. 31 No. 4, pp. 285-296.

Elliott, R. and Jankel-Elliott, N. (2003), "Using ethnography in strategic consumer research", Qualitative Market Research: An International Journal, Vol. 6 No. 4, pp. 215-223.

Elliott, R. and Wattanasuwan, K. (1998), "Consumption and the symbolic project of the self", in Englis, B.G. and Olofsson, A. (Eds), European Advances in Consumer Research Volume 3, Association for Consumer Research, Provo, UT, pp. 17-20.

Emerson, R.M., Fretz, R.I. and Shaw, L.L. (2007), "Participant observation and fieldnotes", in Atkinson, P., Coffey, A., Delamont, S., Lofland, J. and Lofland, L. (Eds), Handbook of Ethnography, Sage, London, pp. 302-320.

Featherstone, M. (2007), Postmodern Consumer Culture, Sage, London.

Firat, A.F. and Dholakia, N. (2006), "Theoretical and philosophical implications of postmodern debates: some challenges to modern marketing", Marketing Theory, Vol. 6 No. 2, pp. 123-162.

Firat, F.A. and Venkatesh, A. (1995), "Liberatory postmodernism and the reenchantment of consumption", Journal of Consumer Research, Vol. 22 No. 3, pp. 239-267.

Goffman, E. (1959), The Presentation of Self in Everyday Life, Anchor, New York, NY.

Goffman, E. (1967), Interaction Ritual: Essays on Face-to-Face Behavior, Anchor, New York, NY.

Framework of abjective consumption 
QMR 21,1

Goffman, E. (1971), Relations in Public: Microstudies of the Public Order, Basic, New York, NY.

Goffman, E. (1974), Frame Analysis: An Essay on the Organization of Experience, Harvard University Press, Cambridge, MA.

Goffman, E. (1981), Forms of Talk, Blackwell, Oxford.

Lee, N. and Goulding, C. (2005), "Grounded theory, ethnography and phenomenology: a comparative analysis of three qualitative strategies for marketing research", European Journal of Marketing, Vol. 39 Nos 3/4, pp. 294-308.

Griffiths, M. and Gilly, M. (2009), “A typology of consumer territorial rudeness”, in McGill, A.L. and Shavitt, S. (Eds), Advances in Consumer Research Volume 36, Association for Consumer Research, Duluth, MN, pp. 769-770.

Heath, C., Hindmarsh, J. and Luff, P. (2010), Video in Qualitative Research: Analysing Social Interaction in Everyday Life, Sage, London.

Heiskala, R. (1999), "From Goffman to semiotic sociology”, Semiotica, Vol. 124 Nos 3/4, pp. 211-234.

Hirschman, E. and Holbrook, M. (1993), The Semiotics of Consumption: Interpreting Symbolic Consumer Behavior in Popular Culture and Works of Art, Mouton, Berlin.

Holt, D.B. (1992), "Examining the descriptive value of ritual in consumer behavior: a view from the field", in Sherry, J.F. Jr and Sternthal, B. (Eds), Advances in Consumer Research Volume 19, Association for Consumer Research, Provo, UT, pp. 213-218.

Homer, S. (2005), Lacaues Lacan, Routledge, London.

Janiszewski, C. (2008), “Goal-directed perception”, in Haugtvedt, C.P., Herr, P.M. and Kardes, F.R. (Eds), The Handbook of Consumer Psychology, LEA, New York, NY, pp. 393-418.

Kang, C., Wooten, D. and Packard, G. (2013), "Secrets and lies: how consumers manage the flow of egothreatening information", in Botti, S. and Labroo, A. (Eds), Advances in Consumer Research Volume 41, Association for Consumer Research, Duluth, MN.

Knoblauch, H. (2012), "Videography: focused ethnography and video analysis", in Knoblauch, H., Schnettler, B., Raab, J. and Soeffner, H.G. (Eds), Video Analysis: Methodology and Methods Qualitative Audiovisual Data Analysis in Sociology, Peter Lang, Frankfurt, pp. 69-84.

Kretz, G. (2010), "Pixelize me! A semiotic approach of self-digitalization in fashion blogs", in Campbell, M.C., Inman, J. and Pieters, R. (Eds), Advances in Consumer Research Volume 37, Association for Consumer Research, Duluth, MN, pp. 393-399.

Kristeva, J. (1982), Powers of Horror: An Essay on Abjection, Columbia University Press, New York, NY.

Lechte, J. (2003), Key Contemporary Concepts: From Abjection to Zeno's Paradox, Sage, London.

Ligas, M. and Coulter, R.A. (2001), "Changing faces in services relationships: customers' roles during dissatisfactory service encounters", in Gilly, M.C. and Meyers-Levy, J. (Eds), Advances in Consumer Research Volume 28, Association for Consumer Research, Valdosta, GA, pp. 71-76.

Menninghaus, W. (2003), Disgust: The Theory and History of a Strong Sensation, SUNY, New York, NY.

Miles, M.B. and Huberman, M.A. (1994), Qualitative Data Analysis, Sage, London.

Mimoun, S.B. and Ammar, O. (2013), "Brands and strategies of self-presentation on Facebook", in Cornelissen, G., Reutskaja, E. and Valenzuela, A. (Eds), European Advances in Consumer Research Volume 10, Association for Consumer Research, Duluth, MN, pp. 95-97.

Nguyen, H., Chen, S. and Mukherjee, S. (2011), "Counter-stigma and achievement of happiness through the freegan ideology", in Dahl, D.W., Johar, G.V. and Van Osselaer, S.M.J. (Eds), Advances in Consumer Research Volume 38, Association for Consumer Research, Duluth, MN.

Pollak, A. (2008), “Analyzing TV documentaries”, in Wodak, R. and Krzyzanowski, M. (Eds), Qualitative Discourse Analvsis in the Social Sciences, Palgrave-Macmilan, New York, NY, pp. 77-95. 
Rossolatos, G. (2014), Brand Equity Planning with Structuralist Rhetorical Semiotics, Kassel University Press, Kassel.

Rossolatos, G. (2015d), "The brand imaginarium, or on the iconic constitution of brand image", in Rossolatos, G. (Ed.), Handbook of Brand Semiotics, Kassel University Press, Kassel, pp. 390-457.

Rossolatos, G. and Hogg, M.K. (2013), "Fetish, taboo, simulacrum: an applied psychoanalytic/semiotic approach to the experiential consumption of music products", Proceedings of the 12th International Marketing Trends Conference, Paris, 17-19 January, available at: www.marketingtrends-congress.com/archives/2013/pages/PDF/770.pdf

Saatcioglu, B. and Ozanne, J. (2010), "The voices of trailer park residents: towards a multidimensional understanding of stigma”, in Campbell, M.C., Inman, J. and Pieters, R. (Eds), Advances in Consumer Research Volume 37, Association for Consumer Research, Duluth, MN, pp. 28-31.

Schenk, T.C. and Holman, R.H. (1980), "A sociological approach to brand choice: the concept of situational self image", in Olson, J.C. and Abor, A. (Eds), Advances in Consumer Research Volume 7, Association for Consumer Research, Minneapolis, pp. 610-614.

Schroeder, J.E. (2009), “The cultural codes of branding”, Marketing Theory, Vol. 9 No. 1, pp. 123-126.

Sherry, J.F. (1991), "Postmodern alternatives: the interpretive turn in consumer research", in Robertson, T. and Karsarjian, H. (Eds), Handbook of Consumer Behavior, Prentice-Hall, NJ, pp. 548-591.

Veer, E. (2009), "Living with the obesity stigma: perceptions of being obese from three cultures", in McGill, A.L. and Shavitt, S. (Eds), Advances in Consumer Research Volume 36, Association for Consumer Research, Duluth, MN, pp. 348-354.

Wägar, K. (2012), "Exploring the mundane and complex: the use of ethnography for studying customer-oriented learning", Qualitative Market Research: An International Journal, Vol. 15 No. 2, pp. 165-187.

Woermann, N. and Kirschner, H. (2015), "Online livestreams, community practices and assemblages: towards a site ontology of consumer community", in Diehl, K. and Yoon, C. (Eds), Advances in Consumer Research Volume 43, Association for Consumer Research, Duluth, MN, pp. 438-442.

Young, M.M. (1991), "Disposition of possessions during role transitions", in Holman, R.H. and Solomon, M.R. (Eds), Advances in Consumer Research Volume 18, Association for Consumer Research, Provo, UT, pp. 33-39.

\section{Further reading}

Goffman, E. (1963), Behavior in Public Places: Notes on the Social Organization of Gatherings, Free Press, New York, NY.

Hviid, J.M. (Ed) (2010a), The Contemporary Goffman, Routledge, London.

Hviid, J.M. (2010b), "Recognition as ritualised reciprocation: the interaction order as a realm of recognition", in Jacobsen, M.H. (Ed.), The Contemporary Goffman, Routledge, London, pp. 199-231.

Limkangvanmongkol, V. (2015), "Brands at the point of no return: understanding \#DRESSFORYOURSELFIE subculture as post-postmodern branding paradigm”, in Wan, E.W. and Zhang, M. (Eds), Asia-Pacifc Advances in Consumer Research Volume 11, pp. 51-56.

Riggins, S.H. (1990), Bevond Goffman: Studies on Communication. Institution, and Social Interaction, Mouton, New York, NY.

Rossolatos, G. (2013a), "Smoke your brains out: death drive as interpretative framework for compulsive consumption acts", paper presented at the 38th Annual Macromarketing Conference, Toronto, 4-7 June, available at: www.academia.edu/2383150/Smoke_your_brains_out_Death_drive_as_ interpretive_framework_for_compulsive_consumption_acts_38_th_Annual_Macromarketing conference_Toronto_Canada_4-7_June_2013_

Framework of abjective consumption

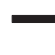


QMR 21,1

Rossolatos, G. (2013b), "Smoke your brains out: death drive as interpretative framework for compulsive consumption acts", paper presented at the 38th Annual Macromarketing Conference, Toronto, 4-7 June, available at: www.academia.edu/2383150/Smoke_your_brains_out_Death_drive_ as_interpretive_framework_for_compulsive_consumption_acts_38_th_Annual_Macromarketing_ conference_Toronto_Canada_4-7_June_2013

Rossolatos, G. (2015a), "Taking the 'multimodal turn' in interpreting consumption experiences", Consumption, Markets and Culture, Vol. 18 No. 5, pp. 427-446.

Rossolatos, G. (2015b), Semiotics of Popular Culture, Kassel University Press, Kassel.

Rossolatos, G. (2015c), "Double or nothing: deconstructing cultural heritage", Chinese Semiotic Studies, Vol. 11 No. 3, pp. 297-315.

Rossolatos, G. (2016a), "Before the consummation what? On the semiotic economy of seduction", Continuum: Iournal of Media \& Cultural Studies, Vol. 30 No. 4, pp. 451-465.

Rossolatos, G. (2016b), "Limeat Inc.: furious Pete and the post-colonial hamburger standard”, available at: http://papers.ssrn.com/sol3/papers.cfm?abstract_id=2717041

Rossolatos, G. (2016c), "A multimodal discourse analytic approach to the articulation of Martini's 'desire' positioning in filmic product placement", Social Semiotics, available at: www.tandfonline. com/doi/full/10.1080/10350330.2016.1189232 (accessed 18 May 2016).

Sandıckc1, O. and Ger, G. (2010), "Veiling in style: how does a stigmatized practice become fashionable?", Journal of Consumer Research, Vol. 37 No. 1, pp. 15-36.

Smith, G. (2006), Erving Goffman, Routledge, London.

Trevino, J.A. (Ed.) (2003), Goffman's Legacy, Rowman \& Littlefield, New York, NY. 


\section{Appendix}

\begin{tabular}{|c|c|c|}
\hline Case ID's & Addiction & web link \\
\hline 1 & Ken (Barbie) human doll & www.youtube.com/watch?v=VetRplyXVoQ \\
\hline 2 & drinking paint & www.youtube.com/watch?v=H1OmlDP-nvU \\
\hline 3 & eating couch cushions & www.youtube.com/watch?v=mkU0akliFwU \\
\hline 4 & eating plastic bags & www.youtube.com/watch?v=cwv6uF0q9GA \\
\hline 5 & drinking human blood & www.youtube.com/watch? $\mathrm{v}=\mathrm{CT}$ xdmVgQQeo \\
\hline 6 & eating sand & www.youtube.com/watch? $\mathrm{v}=$ Y3legpNuj-A \\
\hline 7 & eating vapor & www.youtube.com/watch?v=DV0Th0M7bR4 \\
\hline 8 & eating plastic & www.youtube.com/watch? =Et-QDdQnc3o \\
\hline 9 & eating spay & www.youtube.com/watch?v=-K38aJpAzJc \\
\hline 10 & eating bugs & www.youtube.com/watch?v=vp9ynV-eQWs \\
\hline 11 & ice creams & www.youtube.com/watch?v=CZOqh3nqyS0 \\
\hline 12 & cheesy potatoes & www.youtube.com/watch?v=IJGIMd3_LfY \\
\hline 13 & Soft Pretzels & www.youtube.com/watch?v=Gvt5Byu587U \\
\hline 14 & Rocks for Dinner & www.youtube.com/watch?v=_MaglPJKSmU \\
\hline 15 & Crunching on Dirt & www.youtube.com/watch?v=82FM6PYiZJM \\
\hline 16 & Eating From a Dumpster & www.youtube.com/watch?v=jn8QV3nsHe4 \\
\hline 17 & Mothball Sniffing & www.youtube.com/watch?v=P37x0Af2G6E \\
\hline 18 & Household Cleaner & www.youtube.com/watch?v=bvEFXPJ25p8 \\
\hline 19 & Urine & www.youtube.com/watch? $\mathrm{v}=\mathrm{QyQSBcBBNBQ}$ \\
\hline 20 & I Want To Be A Sofa & www.youtube.com/watch? $\mathrm{v}=\mathrm{oMmsQGnkd9U}$ \\
\hline 21 & Addicted To Burned Sausages & www.youtube.com/watch?v=71UcXFrP9dA \\
\hline 22 & Bread & www.youtube.com/watch?v=QQP2TPrX850 \\
\hline 23 & Fizzy Drinks \& Sweets & www.youtube.com/watch?v=eFPSdwzZ5Sk \\
\hline 24 & Crisps & www.youtube.com/watch?v=m56w9ZjZgm4 \\
\hline 25 & French fries & www.youtube.com/watch?v=SM94IV5GfNg \\
\hline 26 & Maple Syrup & www.youtube.com/watch?v=ac7-8r_YXGA \\
\hline 27 & Bacon & www.youtube.com/watch? $\mathrm{v}=8 \mathrm{JV} 7 \mathrm{mYqlAxc}$ \\
\hline 28 & chocolate & www.youtube $. \mathrm{com} /$ watch? $\mathrm{v}=665 \mathrm{~m} 2 \mathrm{MOy} \mathrm{Wa} 0$ \\
\hline 29 & Fried Chicken & www.youtube.com/watch?v=AIuliq0hBb0 \\
\hline 30 & Spaghetti Hoops & www.youtube.com/watch?v=NJBDTrZFeBU \\
\hline 31 & Biscuits & www.youtube.com/watch?v=uaHGnd9avUc \\
\hline 32 & Siblings addicted to being together & www.youtube.com/watch?v=ZcsR53djWFo \\
\hline 33 & Hair follicles & www.youtube.com/watch?v=i3cpLKHhm3s \\
\hline 34 & I Love My Inflatable Animals & www.youtube.com/watch?v=1h93pguL00A \\
\hline 35 & Eating Cigarette Ashes & www.youtube.com/watch?v=wYdIRVJDEBs \\
\hline 36 & Glass & www.youtube.com/watch?v=YIdzaNbdDYw \\
\hline 37 & blow dryer & www.youtube.com/watch?v=vJy8WFkPoQ4 \\
\hline 38 & skin bleaching & www.youtube.com/watch?v=kyMVgsHazQ4 \\
\hline 39 & Compulsive Cleaner Can’t Stop & www.youtube.com/watch?v=7cwnh59-tNU \\
\hline 40 & Compulsive Scab Picking & www.youtube.com/watch?v=conwDRgiUBI \\
\hline 41 & Cat food & www.youtube.com/watch?v=cok2eBNIN2Y \\
\hline 42 & cheeseburger & www.youtube.com/watch?v=cJ4di4_U6Ks \\
\hline 43 & Hairless Rat Love & www.youtube.com/watch?v=JsZPLKLmgf8 \\
\hline 44 & Huffing Gasoline & www.youtube.com/watch?v=ib5p7F0kRWU \\
\hline 45 & Kesha eats toilet paper & www.youtube.com/watch?v=_kdTZK3-fcY \\
\hline 46 & Dead animal addict & www.youtube.com/watch?v=4 $\mathrm{EGas} 7 \mathrm{njEwI}$ \\
\hline 47 & Looking Like Justin Bieber & www.youtube.com/watch?v=vSk14gy5fsA \\
\hline 48 & Doll love lasts forever & www.youtube.com/watch? $\mathrm{v}=\mathrm{gqUhuX} z \mathrm{HnYY}$ \\
\hline 49 & Celebrity stalking & www.youtube.com/watch?v=7DsMnkvA390 \\
\hline 50 & The king of ketchup & www.youtube.com/watch?v=aLZ_HDVf5DY \\
\hline
\end{tabular}

Eating From a Dumpster

Urine

Addicted To Burned Sausages

Crisps

Bacon

Biscuits

Hair follicles

I Love My Inflatable Animals

Eating Cigarette Ashes

Compulsive Cleaner Can't Stop

cheeseburger

Hairless Rat Love

Huffing Gasoline

Kesha eats toilet paper

Doll love lasts forever

The king of ketchup

\section{Soft Pretzels}

www.youtube.com/watch? $\mathrm{v}=$ VetRplyXVoQ www.youtube.com/watch? $\mathrm{v}=\mathrm{H} 1 \mathrm{OmlDP}-\mathrm{nv}$ www.youtube.com/watch? $=$ cwv6uF0q9GA

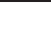

Framework of abjective consumption 
QMR

21,1

62

\begin{abstract}
About the author
George Rossolatos is an academic researcher and marketing practitioner, with experience in advertising (JWT), marketing research (Research International/Millward Brown) and brand management (Colgate-Palmolive, Nestle, Weetabix, Cosmote). He holds a BA (Hons) in Philosophy from the University of Essex, an MSc in Marketing from Manchester Business School and an MBA from Strathclyde Business School and a $\mathrm{PhD}$ in Marketing Semiotics from the University of Kassel. $\mathrm{He}$ is also the editor of the International Journal of Marketing Semiotics (http://ijmarketingsemiotics. com/). Major publications include the Handbook of Brand Semiotics (2015; ed. and co-author), Semiotics of Popular Culture (2015), Brand Equity Planning with Structuralist Rhetorical Semiotics (2012, 2014),//rhetor.dixit//: Understanding ad texts' rhetorical structure for differential figurative advantage (2013), Applying Structuralist Semiotics to Brand Image Research (2012), Interactive Advertising: Dynamic Communication in the Information Age (2002; ed. and co-author), plus numerous articles in trade and academic journals. His research interests focus on branding/ advertising, interpretivist consumer research, new media and cultural studies and span various disciplines such as rhetoric, semiotics, phenomenology, deconstruction, psychoanalysis, communication theory, while encompassing research designs of quantitative, qualitative and mixed methods orientation. Download full CV from http://bit.ly/1cnUnVT. George Rossolatos can be contacted at: georgerossolatos123@gmail.com
\end{abstract}

For instructions on how to order reprints of this article, please visit our website: www.emeraldgrouppublishing.com/licensing/reprints.htm Or contact us for further details: permissions@emeraldinsight.com 